\title{
Prediction of $\beta$-lactoglobulin genotypes based on milk Fourier transform infrared spectra
}

\author{
M. J. M. Rutten, ${ }^{* 1}$ H. Bovenhuis, ${ }^{*}$ J. M. L. Heck, $\dagger$ and J. A. M. van Arendonk ${ }^{*}$ \\ ${ }^{*}$ Animal Breeding and Genomics Centre, Wageningen University, PO Box 338, $6700 \mathrm{AH}$, Wageningen, the Netherlands \\ †FrieslandCampina Research, PO Box 87, 7400 AB, Deventer, the Netherlands
}

\begin{abstract}
$\beta$-Lactoglobulin ( $\beta$-LG) genotypes are associated with differences in bovine milk protein composition. Therefore, $\beta$-LG genotypes are of direct relevance for the dairy industry. In this study, we predicted $\beta$-lactoglobulin genotypes based on routinely recorded milk Fourier transform infrared spectra using 500 calibration samples. The results show that $76 \%$ of the cows carrying the $\beta$-LG AA genotype, $80 \%$ of the cows carrying the $\beta$-LG $\mathrm{AB}$ genotype, and $66 \%$ of the cows carrying the $\beta$-LG $\mathrm{BB}$ genotype were predicted correctly. Furthermore, the prediction of $\beta-\mathrm{LG}$ genotypes based on Fourier transform infrared spectra showed a repeatability of 0.85 . We discuss how the combined use of predicted $\beta$-LG genotypes, pedigree information, and $\beta$-LG genotypes derived using other methods could lead to further improvement in the percentage of correctly predicted $\beta-\mathrm{LG}$ genotypes. The presented methodology is easy and inexpensive and could ultimately provide $\beta$-LG genotypes at the individual cow level.
\end{abstract}

Key words: milk, infrared, $\beta$-lactoglobulin, genotype

\section{INTRODUCTION}

$\beta$-Lactoglobulin genotypes show significant associations with the composition of bovine milk protein (e.g., Lundén et al., 1997; Heck et al., 2009; Bonfatti et al., 2010). Heck et al. (2009) showed that the relative amount of casein in the total milk protein is $3.1 \%$ higher in animals carrying the $\beta$-LG BB genotype compared with animals carrying the $\beta-\mathrm{LG}$ AA genotype. Furthermore, it has been demonstrated that the $\beta$-LG $B$ variant is associated with higher casein content, thus resulting in increased cheese yields (e.g., Van den Berg et al., 1992). In addition to the effect on casein content, $\beta$-LG genotypes are also associated with effects on whey composition (Heck et al., 2009). Further, $\beta$-LG

Received January 5, 2011.

Accepted April 16, 2011.

${ }^{1}$ Corresponding author: marc.rutten@wur.nl genotypes are associated with fouling of heaters due to the different denaturation temperatures of $\beta-\mathrm{LG} \mathrm{A}$ and B protein variants (Hill et al., 1997). Therefore, $\beta$-LG genotypes are of direct relevance for the dairy industry.

The identification of SNP responsible for different $\beta$-LG protein variants (e.g., Ganai et al., 2009) allows straightforward determination of $\beta-\mathrm{LG}$ genotypes in each animal, irrespective of the availability of a milk sample. With the advent of the genomic selection era, most of the AI bulls as well as elite dams have their genotype determined for many SNP. Some of these SNP will map close to or within the $\beta$-LG gene, which enables straightforward selection for the $\beta$-LG genotype more suitable for the selection aims. Alternatives to genotyping at the DNA level are isoelectrofocusing (IEF), electrophoresis, and chromatography of milk protein (Caroli et al., 2009). However, application of chromatography is costly and labor intensive and therefore not feasible for commercial dairy farms, whereas techniques such as IEF are somewhat cheaper and allow simultaneous genotyping of several milk protein variants. Knowledge of $\beta$-LG genotypes might be useful for farmers who manufacture their milk into cheese or when dairy companies start implementing changes in milk payment systems directed toward the valuation of milk protein composition.

The amount of $\beta$-LG protein in milk can be predicted using Fourier transform infrared (FTIR) spectroscopy with moderate success (validation $\mathrm{R}^{2}=0.57$ based on 900 calibration samples; our unpublished data). Because of large differences in the relative amount of $\beta-L G$ in milk protein produced by cows with different $\beta$-LG genotypes, but also due to other differences in their milk composition detectable by FTIR spectroscopy, it might be possible to predict $\beta$-LG genotypes based on milk FTIR spectra. Because FTIR spectroscopy is routinely used to determine, for example, the fat and protein content of milk, the existing infrastructure could be applied to predict $\beta$-LG genotypes of individual cows based on each test-day observation. Therefore, the aim of this study was to investigate the feasibility of predicting $\beta$-LG genotypes based on milk FTIR spectra. 
Table 1. The number of heifers, Fourier transform infrared (FTIR) spectra, FTIR spectra per heifer, $\beta$-LG genotype frequencies, and mean and standard deviation of relative $\beta$-LG production specified for heifers carrying different $\beta$-LG genotypes and for all heifers

\begin{tabular}{|c|c|c|c|c|}
\hline \multirow[b]{2}{*}{ Item } & \multicolumn{3}{|c|}{ Actual $\beta$-LG genotype } & \multirow[b]{2}{*}{ All } \\
\hline & $\mathrm{AA}$ & $\mathrm{AB}$ & $\mathrm{BB}$ & \\
\hline Heifers (n) & 538 & 869 & 262 & 1,669 \\
\hline FTIR spectra (n) & 1,392 & 2,258 & 676 & 4,326 \\
\hline FTIR spectra/heifer (n) & 2.59 & 2.60 & 2.58 & 2.59 \\
\hline Genotype frequency (\%) & 32 & 52 & 16 & 100 \\
\hline$\beta-\mathrm{LG}^{1}$ mean (SD) & $9.56(0.74)$ & $8.15(0.64)$ & $6.56(0.56)$ & $8.35(1.20)$ \\
\hline
\end{tabular}

${ }^{1}$ Expressed on a protein basis $(\mathrm{g} / 100 \mathrm{~g})$; means $(\alpha=0.001)$ and standard deviations $(\alpha=0.05)$ differed significantly between $\beta$-LG genotypes.

\section{MATERIALS AND METHODS}

\section{Milk Sampling and FTIR Recording}

In this study, data of 1,669 Dutch Holstein-Friesian heifers having 1 (0.9\%), 2 (15.4\%), or $3(83.7 \%)$ recorded milk FTIR spectra and $\beta$-LG genotypes were available (Table 1). All heifers were in their first lactation and calving dates varied from June to December 2004. Milk samples were collected during 3 periods in 2005. The first period ranged from February until March 2005 and is referred to as the winter period, the second ranged from March until May 2005 and is referred to as the spring period, and the third ranged from May until June 2005 and is referred to as the summer period. The difference between the winter and summer periods was that in the winter period the heifers were housed indoors and fed silage, whereas in the summer period the heifers were mostly on pasture. In the spring period, both systems were observed. In total, 395 farms in the Netherlands were involved in this study and approximately 5 heifers were sampled per farm, all with at least $87.5 \%$ Holstein-Friesian genes. Milk samples (0.5 L each) were from individual cows at 1 morning milking only. Milk samples were conserved using sodium azide $(0.03 \% \mathrm{wt} /$ wt) and were kept at $4^{\circ} \mathrm{C}$ at all times. Subsequently, FTIR absorption spectra were recorded on 10-mL milk subsamples using MilkoScan FT 6000 equipment (Foss, Hillerød, Denmark) at the certified laboratory of the Milk Control Station (Zutphen, the Netherlands). The FTIR spectra consisted of 1,060 FTIR frequencies (wavenumbers) ranging from 925 to $5,008 \mathrm{~cm}^{-1}$. In an earlier study, capillary zone electrophoresis (CZE) was applied to each of these milk samples to quantify the protein composition of each milk sample (see Heck et al., 2008). Therefore, the average relative amount of $\beta$-LG and the standard deviation were available within each $\beta$-LG genotype class.

\section{$\beta$-LG Genotyping}

Blood samples of the 1,669 heifers were collected for isolation of DNA. Genomic DNA was isolated from 2 $\mathrm{mL}$ of whole blood with the Puregene method (Gentra, Qiagen, Hilden, Germany). The polymorphisms associated with the known protein variants $\beta$-LG (A and B) were genotyped using a SNaPshot assay as described by Visker et al. (2011).

\section{Prediction of the $\beta-L G$ Genotype}

A calibration data set was created by randomly selecting 500 observations out of the available 4,326. Different $\beta$-LG genotypes were represented in the calibration data set according to their frequency in the population. In this way, we mimicked a sampling procedure lacking prior knowledge on actual population $\beta$-LG genotype frequencies. In the calibration set, $32 \%$ of the observations had $\beta$-LG genotype AA, $53 \%$ had $\beta$-LG genotype $\mathrm{AB}$, and $15 \%$ had $\beta$-LG genotype $\mathrm{BB}$ (Table 1 ). The response variable was represented by a dummy variable and coded as -1 when the genetic analysis indicated that the $\beta$-LG genotype was AA, 0 when the $\beta$-LG genotype was $\mathrm{AB}$, and 1 when the $\beta$-LG genotype was $\mathrm{BB}$. The relationships between the response variable and the FTIR spectra were modeled using partial least squares regression, implemented in the $\mathrm{R}$ ( $\mathrm{R}$ Development Core Team, 2008) package "PLS" (Mevik and Wherens, 2007). Spectral wavenumbers from 1,619 $\mathrm{cm}^{-1}$ to $1,673 \mathrm{~cm}^{-1}$ and from $3,069 \mathrm{~cm}^{-1}$ to $3,663 \mathrm{~cm}^{-1}$ were designated as water absorption areas and were removed from the data. The remaining 890 different wavenumbers were used for modeling. The number of latent variables (25) was determined by graphical inspection of the relation between the number of latent variables and the coefficient of determination $\left(R^{2}\right)$ in the validation data set. 
For validation of the FTIR $\beta$-LG prediction model, dummy variables indicating $\beta$-LG genotype were predicted for all observations in the validation data set. Because prediction using the FTIR $\beta$-LG prediction model yields a continuous variable $(\hat{Y})$, a set of decision rules was used to assign each milk sample to a $\beta$-LG genotype:

$$
\begin{gathered}
\hat{\mathrm{Y}} \leq-0.5 \rightarrow \beta-\mathrm{LG} \text { genotype }=\mathrm{AA}, \\
-0.5<\hat{\mathrm{Y}}<0.5 \rightarrow \beta-\mathrm{LG} \text { genotype }=\mathrm{AB}, \\
\hat{\mathrm{Y}} \geq 0.5 \rightarrow \beta-\mathrm{LG} \text { genotype }=\mathrm{BB} .
\end{gathered}
$$

Ten replicates of the calibration-validation procedure were run to obtain means and standard deviations of the percentage of correctly assigned heifers to each $\beta-L G$ genotype. Because 500 observations were included in the calibration data set, $4,326-500=3,826$ observations were in the validation data set.

The repeatability of predicted $\beta$-LG genotypes using multiple milk samples of the same heifers was investigated and quantified by decomposing the variance of predicted $\beta$-LG genotypes with the following model:

$$
\hat{\mathbf{Y}}_{i j}=\mu+I_{i}+\varepsilon_{i j}
$$

where $\hat{\mathrm{Y}}$ is the predicted $\beta$-LG genotype of heifer $i$ based on FTIR spectrum $j, \mu$ is the general mean, $I$ is a random effect of heifer $i$, and $\varepsilon$ is a random residual term. Furthermore, it was assumed that $I \sim N\left(0, \sigma_{I}^{2}\right)$ and $\varepsilon \sim N\left(0, \sigma_{\varepsilon}^{2}\right)$, and genetic relationships between animals were ignored. Therefore, all variance attributable to individual heifers was captured by $\sigma_{I}^{2}$; that is, both genetic and permanent environmental variance. Finally, the repeatability (e.g., Falconer and Mackay, 1996) was calculated as $\sigma_{I}^{2} /\left(\sigma_{I}^{2}+\sigma_{\varepsilon}^{2}\right)$.

\section{RESULTS AND DISCUSSION}

In this study, $538(32 \%)$ heifers carrying the $\beta$-LG AA genotype, 869 (52\%) heifers carrying the $\beta$-LG AB genotype, and $262(16 \%)$ heifers carrying the $\beta$-LG BB genotype participated (Table 1). These heifers had 1,392, 2,258, and 676 FTIR spectra available, respectively, averaging $2.59,2.60$, and 2.58 spectra per heifer in the respective genotype classes. The average relative production of $\beta$-LG was $9.56 \pm 0.74 \mathrm{~g} / 100 \mathrm{~g}$ for the AA genotypes, $8.15 \pm 0.64 \mathrm{~g} / 100 \mathrm{~g}$ for the $\mathrm{AB}$ genotypes, and $6.56 \pm 0.56 \mathrm{~g} / 100 \mathrm{~g}$ for the BB genotypes. All means $(P<0.001)$ and standard deviations $(P<0.05)$ for $\beta$-LG were significantly different between different $\beta$-LG genotype classes.

\section{Prediction of the $\beta-L G$ Genotype}

The results from the 10-fold replicated calibrationvalidation procedure for prediction of $\beta$-LG genotypes are presented in Table 2. Predicted $\beta-\mathrm{LG}$ genotypes based on milk FTIR spectra from heifers carrying an actual $\beta$-LG AA genotype were correct in $76 \pm 4 \%$ of cases. The percentage correct predictions were higher for heifers that carried the $\beta$-LG AB genotype ( $80 \pm$ $7 \%)$ and the $\beta$-LG BB genotype $(66 \% \pm 7 \%)$. On average, a heifer's $\beta$-LG genotype was correctly predicted in $74 \%$ of the cases based on a milk FTIR spectrum. Within the calibration data set, these percentages were $87 \pm 4 \%$ for the AA genotype, $94 \pm 1 \%$ for the $\mathrm{AB}$ genotype, and $79 \pm 4 \%$ for the BB genotype. Therefore, by going from calibration to validation data, the percentage correctly predicted $\beta$-LG genotypes decreased by roughly $13 \%$, which shows that the calibration was quite robust.

To decide which $\beta$-LG genotype a heifer carries, a predicted dummy variable was compared with 2 thresholds in this study. These thresholds were simply set midway between the target values of the 3 different genotypes $(-1,0$, and 1 for $\beta-\mathrm{LG} \mathrm{AA}, \mathrm{AB}$, and $\mathrm{BB}$ genotypes, respectively) and might therefore be sub-optimal. An alternative could be to fit a trivariate mixture of (normal) distributions to the predicted dummy variables and subsequently derive probabilities to assign heifers certain $\beta$-LG genotypes. Other aspects of the presented methodology might also be eligible for further optimization; for example, the number and choice of predictor variables (FTIR wavenumbers) and the number of latent variables used. Bayesian methods might prove very suitable for this purpose; however, this area was not explored because it was beyond the scope of this study.

Recently, Berget et al. (2010) used a similar approach to discriminate between milk samples from goats carrying different $\alpha_{S_{1}}$-casein haplotypes. Some of these haplotypes are characterized by single point deletions leading to reduced levels of the $\alpha_{S 1}$-casein protein in milk. Berget et al. (2010) were successful in discriminating milk samples from animals that were homozygous for either "strong" or "weak" haplotypes but not in discriminating milk samples from heterozygous animals from either one of the former two. In the current study, it was possible to discriminate heifers carrying heterozygous $\beta$-LG genotypes from heifers carrying homozygous $\beta$-LG genotypes. This could be due to many reasons; for example, the number of milk samples used 
Table 2. Average percentage of correctly predicted $\beta$-LG genotypes ( \pm SE) for $n=3,826$ milk Fourier transform infrared (FTIR) spectra ${ }^{1}$

\begin{tabular}{lccc}
\hline & \multicolumn{3}{c}{ Actual $\beta$-LG genotype } \\
\cline { 2 - 4 } Genotype & $\mathrm{AA}$ & $\mathrm{AB}$ & $\mathrm{BB}$ \\
prediction & $(\mathrm{n}=1,232)$ & $(\mathrm{n}=1,993)$ & $(\mathrm{n}=601)$ \\
\hline $\mathrm{AA}$ & $76 \pm 4$ & $12 \pm 3$ & $33 \pm 6$ \\
$\mathrm{AB}$ & $23 \pm 4$ & $80 \pm 7$ & $66 \pm 7$ \\
$\mathrm{BB}$ & 100 & $8 \pm 4$ & 100 \\
Total & 100 & \\
1.The $\beta$-LG genotype was predicted using an FTIR prediction model based on 500 calibration samples and 25 \\
latent variables; these values were obtained by repeating the calibration-validation procedure 10 times.
\end{tabular}

by Berget et al. (2010) was much lower compared with that in the current study. In addition, the caseins $\left(\alpha_{\mathrm{S}^{-}}\right.$, $\alpha_{\mathrm{S}^{-}}$, and $\beta$-casein) are present in micelle form in liquid milk, with $\kappa$-casein forming the outer layer, which might prevent proper detection of $\alpha_{\mathrm{S} 1}$-casein by FTIR spectroscopy. Another reason might be that variation in production of $\alpha_{\mathrm{S}_{1}}$-casein protein within homozygous and heterozygous haplotypes is relatively large and compromises discrimination of the different haplotypes. Other factors, such as dominance or interaction effects, could also be involved.

It was stated earlier that the amount of $\beta$-LG protein in milk can be predicted using FTIR with moderate success (validation $\mathrm{R}^{2}=0.57$ based on 900 calibration samples; our unpublished data). The correlation between observed and predicted $\beta$-LG protein is therefore $\sqrt{ } 0.57=0.75$, which is close to the mean percentage of correctly predicted $\beta$-LG genotypes. Although not directly comparable, this correlation suggests that the use of the predicted amount of $\beta$-LG to assign heifers to $\beta$-LG genotype classes could be just as successful. Verification of the latter, however, indicated that the use of the FTIR-predicted amount of $\beta$-LG resulted in an average percentage correctly predicted $\beta-\mathrm{LG}$ genotypes of $64 \%$, which is $10 \%$ lower (data not shown). The information contained in the FTIR data, therefore, seems only fully exploitable when contrasts between different $\beta$-LG genotypes are used in modeling.

The existing infrastructure for FTIR analysis of milk samples allows several measurements on the same animals throughout the year. This could be beneficial for the accuracy of $\beta$-LG genotype prediction when the repeatability is low. In this study, however, the average estimated repeatability was 0.85 . This means, on the one hand, that repeated measurements do not have much added value for increasing the accuracy of $\beta$-LG genotype prediction. On the other hand, this also means that only a few measurements are required to be able to predict $\beta$-LG genotypes with accuracies as presented earlier. Further increases in prediction accuracy could be achieved by combining FTIR $\beta$-LG genotype predictions with methods used for predicting genotypes based on pedigree information; for example, the gene content estimation method as proposed by Gengler et al. (2007). By using the gene content estimation method, all known genetic relationships included in the pedigree, as well as known $\beta$-LG genotypes, can be combined with predicted $\beta-\mathrm{LG}$ genotypes. Consequently, a proportion of the incorrectly predicted $\beta$-LG genotypes can be identified and corrected. A few iterations of gene content estimation followed by identification of incorrectly FTIR predicted $\beta$-LG genotypes and subsequent correction can lead to the highest obtainable accuracy with respect to gene content estimation for the $\beta$-LG gene. An additional benefit of the gene content estimation method is that cows that do not participate in milk control can get a predicted $\beta$-LG genotype through pedigree relationships to other animals. The combination of the presented $\beta$-LG genotype prediction method and the gene content estimation method (Gengler et al., 2007) could provide predicted $\beta$-LG genotypes for virtually all individual cows at the farm level.

The presented methodology to predict $\beta-\mathrm{LG}$ genotypes based on milk FTIR spectra assumed that the experimental material used was free of errors, something that is not obvious. In the present case, several control steps were taken to minimize the number of potential mistakes because these could affect the presented results. As indicated earlier, $\beta-\mathrm{LG}$ genotypes (and approximately 30 other SNP) were determined by $2 \mathrm{SNaPshot}$ assays for all heifers and their sires, but in addition, approximately half of the heifers had been genotyped previously using a 1.5K SNP-chip (see Schopen et al., 2009). Both of these sets of SNP were used to check whether genotypes were logical according to pedigree information. Heifers showing conflicting genotypes were discarded from the data. In addition to genotypes, $\beta$-LG protein variants from each milk sample were determined by CZE (see Heck et al., 2008) and checked with $\beta$-LG genotypes.

Implementation of the presented methodology requires collection of data to construct a calibration data 


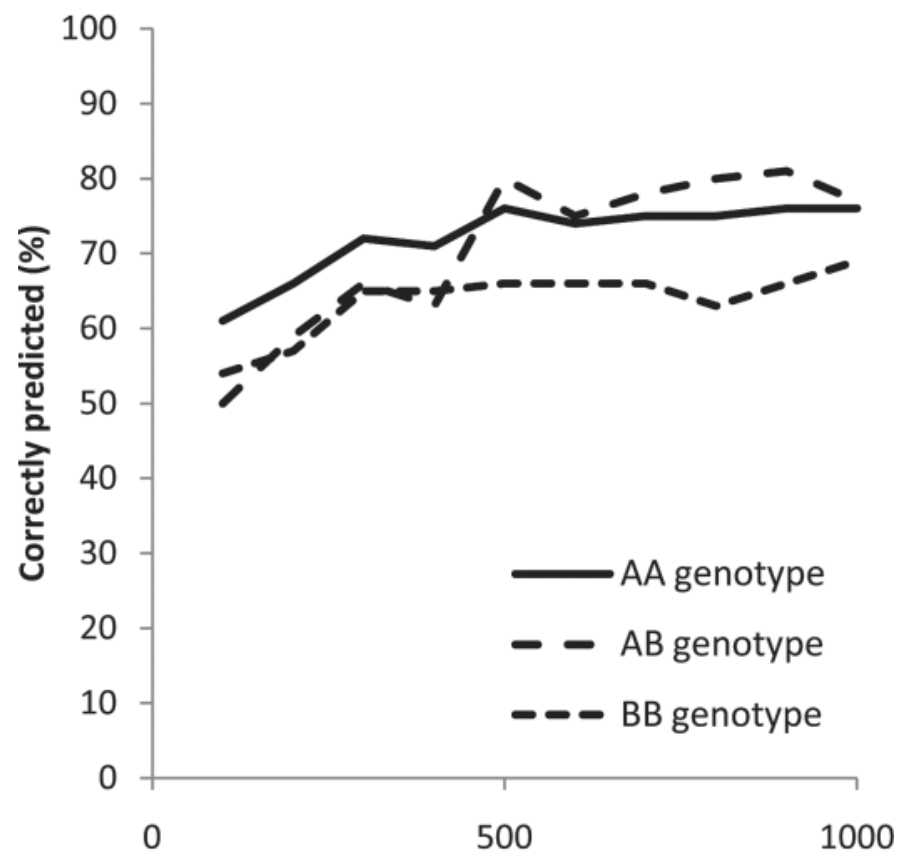

Calibration samples ( $n$ )

Figure 1. The relation between the number of calibration samples and the percentage of correctly predicted $\beta-\mathrm{LG}$ genotypes in the validation data set.

set including known $\beta$-LG genotypes and milk FTIR spectra. To be able to make a proper cost-benefit analysis, the influence of the number of calibration samples on the percentage of correctly predicted $\beta$-LG genotypes was investigated (Figure 1). Figure 1 shows that the percentage of correctly predicted $\beta-\mathrm{LG}$ genotypes increased until 300 calibration samples were included. After this, only the percentage of correctly predicted $\beta-\mathrm{LG} \mathrm{AB}$ genotypes increased until 500 calibration samples were included. According to Figure 1, going beyond 500 calibration samples does not improve the prediction results to a large extent. In addition to the number of calibration samples, season of milk sampling can affect milk composition, especially in dairy systems in which cows are on pasture in summer but are fed silage in winter. This, in turn, could have an effect on predictability of, in this case, $\beta$-LG genotypes, in different seasons. The milk samples used in this study were collected in 3 different seasons. However, using milk samples from only one season in the calibration data set did not influence the results in any case (data not shown). One explanation might be that most of the variation in the relative production of $\beta$-LG is genetic $\left(\mathrm{h}^{2}=0.80\right.$; Schopen et al., 2009), and that seasonal variation is therefore limited.

Several methods are available to accurately determine the genotype at the $\beta$-LG gene; for example, DNA- based genotyping, CZE, or IEF. These methods also allow for simultaneous genotyping of other important milk protein variants. However, the presented method is cheaper and makes use of the existing infrastructure of routine milk control. The current method could be used to predict genotypes for all genes that have known effects on milk composition regardless of whether these genes act on the composition of fat or protein or other milk constituents (e.g., the DGAT1 gene; Schennink et al., 2007). The only prerequisite is that these constituents should be detectable by FTIR.

\section{Relevance of $\beta-L G$ Genotypes}

Knowledge on the $\beta$-LG genotype of cows is important because the $\beta$-LG genotype is associated with several aspects that are important for the dairy industry. The $\beta$-LG $\mathrm{B}$ variant is, for example, associated with higher cheese yields because of its association with higher casein concentrations in milk (Van den Berg et al., 1992). Ultimately, using the proposed system, $\beta$-LG genotypes could become available for many individual cows. Knowledge on $\beta-L G$ genotypes might be useful for farmers who manufacture their milk into cheese or when dairy companies start implementing changes in milk payment systems directed toward the valuation of milk protein composition. Furthermore, the $\beta$-LG $B$ variant is associated with a lower concentration of $\beta$-LG in milk. The latter, in combination with a higher denaturation temperature of the $\beta$-LG B variant (Boye et al., 2004), results in lower fouling rates of heaters during processing of milk (Hill et al., 1997). Furthermore, the $\beta$-LG $\mathrm{B}$ variant is associated with a change in the composition and properties of the whey: more $\alpha$-LA and less $\beta$-LG is produced. Human milk does not contain $\beta$-LG and has a relatively high concentration of $\alpha$-LA (de Wit, 1998); therefore, whey composition associated with the $\beta$-LG B variant is beneficial when used as ingredient for infant nutrition.

\section{CONCLUSIONS}

This study shows that $\beta$-LG genotypes $\mathrm{AA}, \mathrm{AB}$, and $\mathrm{BB}$ can be predicted correctly based on a milk sample FTIR spectrum with an average probability of $74 \%$ of making the correct classification. The proposed method is easy and inexpensive and, although other moreprecise methods exist, this method has the advantage that it could provide $\beta-\mathrm{LG}$ genotypes for virtually all individual cows at the farm level.

\section{ACKNOWLEDGMENTS}

This study was part of the Milk Genomics Initiative and the project "Melk op maat," funded by Wagenin- 
gen University, the Dutch Dairy Association (NZO, Zoetermeer, the Netherlands), CRV (cooperative cattle improvement organization, Arnhem, the Netherlands), the Dutch Technology Foundation (STW, Utrecht, the Netherlands), the Dutch Ministry of Economic Affairs (The Hague, the Netherlands), and the provinces of Gelderland (Arnhem, the Netherlands) and Overijssel (Zwolle, the Netherlands). The authors acknowledge the participating herd owners and the Dutch Milk Control Station (Qlip, Zutphen, the Netherlands).

\section{REFERENCES}

Berget, I., H. Martens, A. Kohler, S. K. Sjurseth, N. K. Afseth, B. Narum, T. Adnøy, and S. Lien. 2010. Caprine CSN1S1 haplotype effect on gene expression and milk composition measured by Fourier transform infrared spectroscopy. J. Dairy Sci. 93:4340-4350.

Bonfatti, V., G. Di Martino, A. Cecchinato, D. Vicario, and P. Carnier. 2010. Effects of $\beta$ - $\kappa$-casein (CSN2-CSN3) haplotypes and $\beta$-lactoglobulin (BLG) genotypes on milk production traits and detailed protein composition of individual milk of Simmental cows. J. Dairy Sci. 93:3797-3808.

Boye, J. I., C. Y. Ma, and A. Ismail. 2004. Thermal stability of $\beta$-lactoglobulins A and B: Effect of SDS, urea, cysteine and Nethylmaleimide. J. Dairy Res. 71:207-215.

Caroli, A. M., S. Chessa, and G. J. Erhardt. 2009. Invited review: Milk protein polymorphisms in cattle: Effect on animal breeding and human nutrition. J. Dairy Sci. 92:5335-5352.

de Wit, J. N. 1998. Nutritional and functional characteristics of whey proteins in food products. J. Dairy Sci. 81:597-608.

Falconer, D. S., and T. F. C. Mackay. 1996. Introduction to Quantitative Genetics. 4th ed. Longmans Green, Harlow, Essex, UK.

Ganai, N. A., H. Bovenhuis, J. A. M. van Arendonk, and M. H. Visker. 2009. Novel polymorphisms in the bovine beta-lactoglobulin gene and their effects on beta-lactoglobulin protein concentration in milk. Anim. Genet. 40:127-133.

Gengler, N., P. Mayeres, and M. Szydlowski. 2007. A simple method to approximate gene content in large pedigree populations: Appli- cation to the myostatin gene in dual-purpose Belgian Blue cattle. Animal 1:21-28.

Heck, J. M. L., C. Olieman, A. Schennink, H. J. F. van Valenberg, M. H. P. W. Visker, R. C. R. Meuldijk, and A. C. M. van Hooijdonk. 2008. Estimation of variation in concentration, phosphorylation and genetic polymorphism of milk proteins using capillary zone electrophoresis. Int. Dairy J. 18:548-555.

Heck, J. M. L., A. Schennink, H. J. F. van Valenberg, M. H. P. W. Visker, H. Bovenhuis, J. A. M. van Arendonk, and A. C. M. van Hooijdonk. 2009. Effects of milk protein variants on the protein composition of bovine milk. J. Dairy Sci. 92:1192-1202.

Hill, J. P., M. J. Boland, and A. F. Smith. 1997. Effect of beta-lactoglobulin variants on milk powder manufacture and properties. Pages 372-394 in Milk Protein Polymorphism. International Dairy Federation Special Issue 9702. IDF, Brussels, Belgium.

Lundén, A., M. Nilsson, and L. Janson. 1997. Marked effect of $\beta$-lactoglobulin polymorphism on the ratio of casein to total protein in milk. J. Dairy Sci. 80:2996-3005.

Mevik, B. H., and R. Wherens. 2007. The PLS package: Principal component and partial least squares regression in R. J. Stat. Softw. 18:1-24.

R Development Core Team. 2008. R: A Language and Environment for Statistical Computing. R Foundation for Statistical Computing, Vienna, Austria.

Schennink, A., W. M. Stoop, M. H. P. W. Visker, J. M. L. Heck, H. Bovenhuis, J. J. van der Poel, H. J. F. van Valenberg, and J. A. M. van Arendonk. 2007. DGAT1 underlies large genetic variation in milk-fat composition of dairy cows. Anim. Genet. 38:467-473.

Schopen, G. C. B., J. M. L. Heck, H. Bovenhuis, M. H. P. W. Visker, H. J. F. van Valenberg, and J. A. M. van Arendonk. 2009. Genetic parameters for major milk proteins in Dutch Holstein-Friesians. J. Dairy Sci. 92:1182-1191.

Van den Berg, G., J. T. M. Escher, P. J. de Koning, and H. Bovenhuis. 1992. Genetic polymorphism of $\kappa$-casein and $\beta$-lactoglobulin in relation to milk composition and processing properties. Neth. Milk Dairy J. 46:145-168.

Visker, M. H. P. W., B. W. Dibbits, S. M. Kinders, H. J. F. van Valenberg, J. A. M. van Arendonk, and H. Bovenhuis. 2011. Association of bovine $\beta$-casein protein variant I with milk production and milk protein composition. Anim. Genet. 42:212-218. doi:10.1111/j.1365-2052.2010.02106.x. 